\title{
La internalización del discurso racista en los jóvenes asháninkas $^{1}$
}

\section{The Internalization of the Racist Discourse in Ashaninka Young People}

\author{
Nila Vigil Oliveros \\ Universidad San Ignacio de Loyola \\ nila.vigil@usil.pe \\ Roberto Zariquiey \\ Pontificia Universidad Católica del Perú \\ rzariquiey@pucp.edu.pe
}

\section{Resumen}

El objetivo de este artículo es dar cuenta de cómo el discurso racista de las élites de la ciudad de Satipo (provincia de la Selva Central del Perú) ha calado en los jóvenes estudiantes asháninka (pueblo indígena arawak) que han migrado de sus comunidades para hacer estudios profesionales en la ciudad.

Palabras clave: Análisis Crítico del Discurso, asháninka, colonización mental, racismo, estudiantes.

\section{Abstract}

The aim of this article is explaining, through the Critical discourse analysis (CDA), how the racist discourse of the elites of the city of Satipo (province of the Rainforest of Peru) has penetrated and it has naturalized into the young Ashaninka students who have migrated from their communities to do their professional studies in the city.

Keywords: Critical Discourse Analysis, Asháninka, Mental Colonization, Racism, Students. 


\section{Introducción}

Como se sabe, el Análisis Crítico del Discurso busca desenmascarar el discurso de las élites que naturalizan y perpetúan el poder a través de sus prácticas discursivas colonizadoras. Se entiende discurso como lo define Van Dijk (2001, p. 191): «un evento comunicativo específico, en general, y una forma escrita u oral de interacción verbal o de uso del lenguaje, en particular». Asimismo, se sigue a Van Dijk en su noción de racismo de las élites (ibid):

[L]as formas más perjudiciales de racismo contemporáneo, a saber, las de las élites. Las élites políticas, burocráticas, corporativas, mediáticas, educativas y controlan las dimensiones y decisiones más cruciales de la vida cotidiana de las minorías [...] tales representaciones mentales racistas típicamente se expresan, formulan, defienden y legitiman en el discurso y pueden por lo tanto reproducirse y compartirse dentro del grupo dominante. Es esencialmente de esta manera en que el racismo es 'aprendido' en la sociedad.

(Van Dijk, 2001, p. 191)

La élite, entonces, es el grupo de poder que busca perpetuar el orden de las cosas y oprimir a las poblaciones minorizadas; en este caso, las élites son el grupo mestizo que ocupa cargos importantes en la ciudad y la población minorizada, los asháninkas que han migrado de sus comunidades al centro de Satipo.

Este documento no presenta un estudio típico de análisis crítico del discurso, ya que no se analiza el discurso de los sectores hegemónicos sino el de un grupo de jóvenes indígenas que estudia en la ciudad de Satipo. Es interesante comprobar hasta qué punto, estos jóvenes reproducen el discurso de la sociedad dominante de la ciudad; es decir, el discurso que discrimina a los asháninkas. En ese sentido, los jóvenes asháninkas terminan por despreciar prácticas culturales que pertenecen a sus padres y abuelos, a ellos mismos. Queremos, entonces, dar cuenta de cómo se producen estos discursos de colonización mental en estos jóvenes en particular.

Para llevar a cabo esta investigación se analizaron diez entrevistas informales a jóvenes asháninkas entre 19 y 22 años que viven en la Municipalidad de Río Tambo, Satipo y estudian en institutos de educación superior que están más o menos a una hora a pie del Municipio. Las actividades académicas son en las 
tardes de 4 a 9 p.m. En Satipo, estos jóvenes pueden hacer distintas actividades; y si bien algunos se emplean como macheteros para los colonos, parece que se dedican exclusivamente a sus estudios. Los que tienen dinero van a cabinas de internet, no solo a consultar las cuestiones para sus tareas. Estas entrevistas fueron transcritas literalmente y de ellas hemos extraído los párrafos a los que hemos aplicado el ACD.

Creemos importante señalar que todos los jóvenes entrevistados han sido niños afectados por la violencia política y nos ha llamado la atención que en ninguna entrevista los jóvenes nos hayan hablado de lo que el conflicto armado interno significó para ellos. Es menester tomar el silencio de estos jóvenes como el signo de algo. El silencio aquí es una voz de alerta.

En cuanto al tipo de ACD llevado a cabo, se realiza una lectura deconstructiva en la que se cuestionan y problematizan creencias, suposiciones e interpretaciones de la realidad que son consideradas verdades incuestionables (Infante et al., 2011).

\section{El contexto en que estudian los jóvenes asháninkas}

Debemos decir que la ciudad de Satipo es una ciudad mestiza donde los asháninkas son discriminados. Una manera de ilustrar esta sociedad racista la encontramos en la plaza de Armas de la ciudad, donde se halla esta placa:

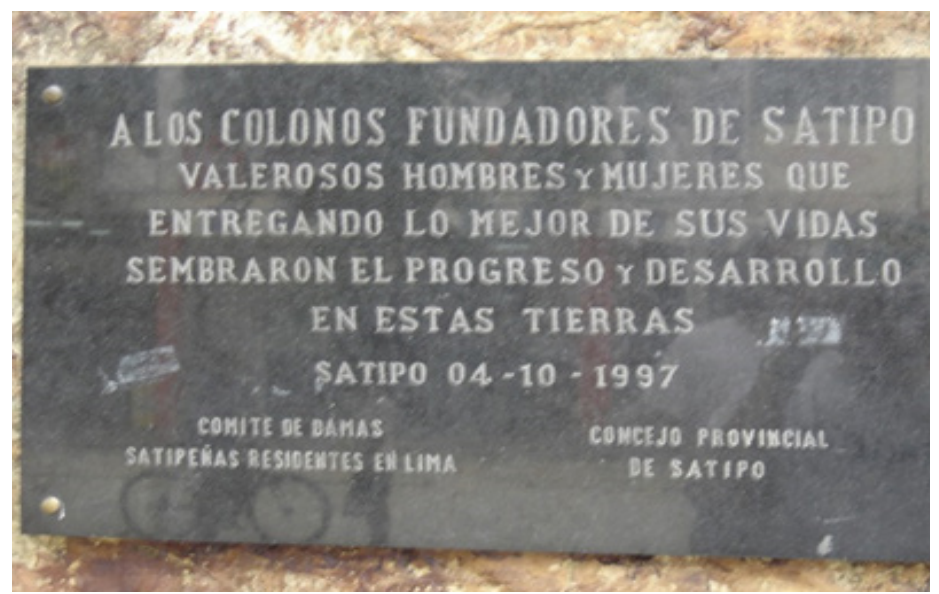

Fig. 1: Placa en la plaza de armas de la ciudad de Satipo 
Satipo está situada en un territorio donde han vivido los asháninkas desde mucho tiempo antes de que lleguen los colonos. No era una tierra vacía como lo podría sugerir la placa. Como sabemos, una de las formas de la discriminación es la invisibilización del otro. Aquí opera esa forma. Se considera que Satipo existe desde su fundación; es decir, desde la llegada de los mestizos. No se dice nada de la usurpación del territorio a los indígenas. Esto es silenciado por los hablantes/escritores de la placa. No se reconoce que es un territorio de otros. Todo ello ha sido borrado. Se identifica a los colonos como los sembradores del progreso y el desarrollo. Sin que se diga nada, se establece que los asháninkas representa el retraso y el subdesarrollo.

A pocos metros de esa placa, en la misma plaza de Armas de Satipo, se encuentra un monumento a un franciscano y en él se puede leer:

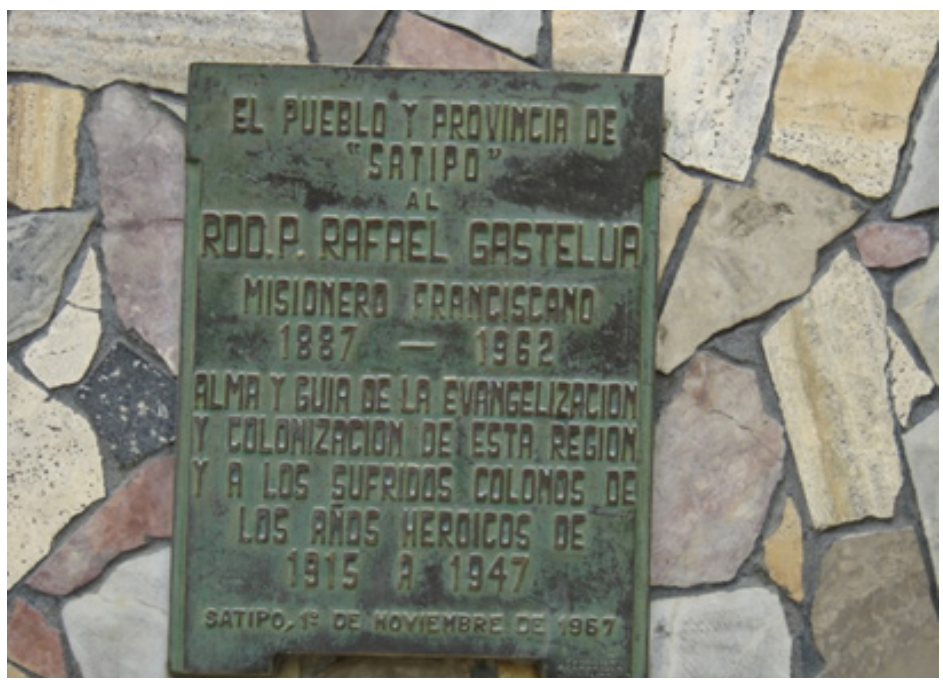

Fig. 2: Placa al misionero franciscano Rafael Gastelua

El franciscano es alma y guía de la evangelización y la colonización, y los colonos son sufridos. Como se ve, ni se menciona a quienes fueron el objeto de la evangelización. El discurso racista de las élites siempre contrasta el grupo de nosotros y el grupo de los otros. Hay varias formas de demostrar el racismo hacia los otros, la invisibilización es la que opera en este discurso. Los colonos son sufridos: quienes usurparon un territorio, son ahora vistos como víctimas. $\mathrm{Pu}-$ dieron resistir esos sufrimientos porque tuvieron un guía: el franciscano. Así, este monumento testimonia los valores mestizos de la religión y la colonización. 


\section{Nila Vigil Oliveros y Roberto Zariquiey}

Las dos inscripciones en la plaza evidencian una forma de racismo solapado. No son discursos abiertamente racistas. Son discursos de autopresentación positiva, donde los hechos reciben nuevos nombres. La dominación se presenta como modernización, la colonización, como sacrificio. No estamos, pues, ante un discurso explícitamente racista sino ante una de las formas más sutiles de discriminación que es la invisibilización del otro.

Van Dijk propone el siguiente cuadrado valórico/ideológico para explicar el discurso discriminatorio de las élites:

- Resaltar todo lo bueno del "nosotros"

- Resaltar todo lo malo de "ellos"

- Mitigar todo lo bueno de "ellos"

- Mitigar todo lo malo del "nosotros"

La estrategia que podemos encontrar en las placas es la radicalización del mitigar lo malo del nosotros. Los textos de esas placas tienen la función de ocultar, legitimar y manipular un hecho históricamente conocido colonización y convertirlo en fundación de hombres sacrificados y valerosos. Así, se deslegitima al ellos y se beneficia al nosotros.

\section{2.- Análisis del discurso de los jóvenes}

2.1. Naturalización de las formas negativas de los otros: "Salir adelante" como forma de huir de la discriminación.

Yo quisiera que mi hermanita salga adelante. Que tenga su profesión, para que no esté en eso que la hace la sociedad, la... discriminación.

Este párrafo es por demás inocente, pero nos muestra hasta dónde se ha asimilado el discurso de las élites. El joven ha experimentado el racismo por ser asháninka y ve como salida de ello tener una profesión, lo que significaría parecerse más a los mestizos.

2.2. Apropiación de la idea que minimiza los aspectos negativos que "los otros" tienen sobre "nosotros".

Los asháninka pertenecen a la familia etnolongüística Arawak y son nombrados nativos o campas en sentido peyorativo. Campa es un sustantivo que realmen- 
te es tomado como insulto por un asháninka pero resulta interesante observar cómo, cuando se les pregunta al respecto, ellos tratan de minimizar la carga discriminativa que sienten cuando así se los llama:

Cuando uno, de repente, te dice campa, alguno les parecerá incómodo, pero para qué sentirse incómodo si yo soy, para que avergonzarse, para qué si me está diciendo mi verdad, si me está diciendo lo que yo soy, para que avergonzarme, más bien me dolería si me dicen serrano eso sí me dolería a mí porque no lo soy.

En este párrafo el joven refiere no sentirse discriminado si es llamado campa, pero asegura también que quizá a otros de su grupo sí les puede parecer incómodo. Aquí la pregunta sería por qué a él no y a otros sí. El joven dice: $M e$ está diciendo mi verdad. Asumiría, entonces, que este calificativo, que es racista, le es propio. Quizá se pueda decir, desde una perspectiva optimista, que el joven se autoafirma como campa y reivindica el término. Luego señala que si se le llamase serrano, sí le dolería porque no lo es. Empieza a hacer aparición entonces un nuevo sistema arbóreo de discriminación como aquel del que nos hablaba Rivera Cusicanqui o las agresiones empiezan a ser combatidas con otras agresiones: serrano se convierte en término peyorativo del cuál sí podría estar dolido si es así calificado.

\subsection{Asimilación de la ideología lingüística imperante: la subalternización de la lengua propia.}

Schieffelin, Woolard, y Kroskrity son los principales expositores de las ideologías lingüísticas, entendidas estas como las ideas que tienen las personas sobre el valor, la estética, la pureza de una lengua. Los autores sostienen que las ideologías lingüísticas son representaciones culturales, de manera implícita o explícita de la intersección de la lengua y los seres humanos en un mundo social. A partir de la ideología lingüística, que cree que una lengua es mejor que otra, se está discriminando no a las lenguas, puesto que sabemos que las lenguas no existen como realidades sino a partir de sus hablantes, así, la discriminación es a los hablantes de la misma. Una forma de discriminación lingüística se da al distinguir entre lengua y dialecto, donde se reserva el estatus de lengua para aquellas lenguas que hablan los grupos de poder y se usa el término dialecto para las lenguas de los grupos minorizados. Hemos escuchado en todos los entrevistados referirse a su lengua como idioma o dialecto. 
Ahorita estoy aquí y él a mi amigo Edgar voy a intercambiar mis ideas, o enseñarlo a mi dialecto, a mi forma de hablar como se puede pronunciar. Él también me tiene que enseñar a su forma de hablar a su forma de decir en quechua.

Edgar es un mestizo que sabe quechua. El joven que hace el comentario es un asháninka que se refiere a su lengua como mi dialecto.

En las asambleas se habla puro idioma, pero a veces los que dirigen hablan castellano.

Es importante señalar que cuando se les pregunta qué lenguas hablan, ellos responden que hablan castellano e idioma, en ese orden. También, tomar en cuenta que según Van Dijk (1997, p. 22) «el orden de palabras [...] puede describirse no solo como estructuras abstractas, como se hace en lingüística, sino también en términos de las realizaciones estratégicas de los usuarios del lenguaje en acción». Referirse a su lengua como dialecto o como idioma tiene una connotación negativa. Si bien no se ha ahondado mucho en el sentido peyorativo del término, es sabido que dialecto se usa, en sentido no técnico, para referirse a una lengua considerada inferior; idioma también es usado con una connotación de valoración negativa, no solo por los asháninkas sino por los habitantes de la selva peruana, indígenas o no, para referirse a las lenguas indígenas.

Dada la recurrencia en los entrevistados a referirse al asháninka como dialecto, se le preguntó el asunto directamente a uno de los jóvenes:

Entrevistador: ¿Y por qué me dijiste que tu dialecto es el asháninka?

Estudiante: ¿Por qué hablo?, porque mis padres son asháninkas

Entrevistador: Ah no, ¿por qué me dijiste que es un dialecto?

Estudiante: ¡Dialecto , donde nosotros conversamos, donde nosotros

hablamos pe'

Entrevistador: ¿Entonces no es una lengua?

Estudiante: No, es una... es un idioma, no es una lengua pe'

Entrevistador: ¿No es una lengua el asháninka?

Estudiante: Leng... eso sí, un poco me decía ahorita, estoy recordando 
Como se observa, el joven duda si el asháninka puede ser considerado una lengua. El distingue lengua de idioma o dialecto. Para él existe una estratificación, y solo cataloga como lengua a la hegemónica. En los grados inferiores de su escala estarían lo que él considera dialectos o idiomas. Como ya se ha dicho, esta es una idea generalizada, no solo con los indígenas de selva central sino con todos los de la Amazonía peruana.

Cuando se ha preguntado a los estudiantes si creen que es necesario hablar asháninka, todos responden afirmativamente. No ha habido un estudiante que diga que no se debería hablar asháninka. Pero cuando se les pregunta qué lenguas hablan, ellos contestan que hablan castellano y asháninka, aunque el asháninka solo lo hablan con gente que no sabe castellano. Es decir, si ellos están con personas que tienen en el asháninka su lengua materna, pero saben castellano, optan por el castellano. A la pregunta de por qué es importante hablar asháninka, la respuesta ha sido:

hablamos en idioma para que puedan hacer comprender a los que no entiendan castellano.

Nótese que la respuesta no ha sido hablamos asháninka, sino hablamos idioma; y que este solo se usa con quien no sabe castellano y solo sirve para que comunicarse con quien no es bilingüe. Es decir, para el muchacho, el castellano le sirve para comunicar todo lo que él quiere. La idea de que el asháninka sehabla cuando el otro no sabe castellano escomún enlosjóvenes.

- ¿Con tus papas qué hablas?

- Asháninka. Mis papás no comprende castellano porque ha vivido más.

- ¿Con tus hermanos?

- En castellano porque ya entienden. 
El asháninka, entonces, sería una lengua "transicional." Cuando los asháninkas entienden castellano, no tendría sentido hablar en asháninka. Se está en un caso extremo de debilitamiento lingüístico. Se califica de extremo porque en situaciones de dominación y colonialismo, donde hay una lengua dominante y una oprimida, se usa la lengua del dominante para los procesos comunicativos entre los dos grupos. Como se nota, se está ante hablantes de un solo grupo, el grupo de los oprimidos, que le da privilegio comunicativo al castellano y rechaza su propia lengua. El uso del castellano incluso en los espacios propios es una muestra de que la dominación de la cultura es fuerte. Si la lengua, según Bordieau, es un instrumento de dominación simbólica de primera magnitud (En Bourdieu y Wacquant 1992), el uso del castellano entre hermanos asháninka que hablan asháninka nos dice hasta dónde ha llegado tal dominación.

La deslealtad lingüística es clara y es menester tener presente que esta no se da porque los hablantes optaron por dejar el asháninka, sino porque algo los ha llevado a tomar esa decisión. Es importante encontrar la causa y ver si es posible revertirla. Vale la pena recordar, una vez más, que los estudiantes han sido sometidos a la escuela castellanizante, "civilizadora" y desaprendedora de lo propio. A los estudiantes se les ha inculcado la idea de que hablar asháninka es motivo de vergüenza:

- ¿Hay gente que se avergüence de hablar asháninka?

- Los que salen del colegio se avergüenzan de hablar. Porque los mayores no se avergüenzan de hablar en idioma [asháninka], hacen sus bromas, sus chistes en asháninka.

Cuando se le preguntó a un joven si eran los hombres o las mujeres quienes hablaban más asháninka, su respuesta fue:

Las mujeres hablan más asháninka, los hombres hablan más castellano. Las mujeres tienen vergüenza de hablar castellano.

Se menciona la palabra vergüenza. Las mujeres tienen vergüenza de hablar castellano por miedo al error. ¿Quiénes avergüenzan a las mujeres cuando hablan castellano? Pues los asháninkas mismos. Hay una nueva forma de discriminación hacia la mujer asháninka por parte de sus mismos paisanos. Si las mujeres se avergüenzan, es debido a burlas por parte de los hombres. Como se ve, los jóvenes han asimilado una las formas de discriminación de la sociedad mestiza: la discriminación ante las variedades de castellano. Si las mujeres hablan más asháninka es porque ellas han tenido menos oportunidades de aprender 
castellano y no por una cuestión de lealtad a su lengua. Como se sabe, la mujer indígena tiene menos oportunidades de acceso a la escuela que los hombres. Estas mujeres han sido menos expuestas a la escuela castellanizante y, por ello, hablan más asháninka. Se observa, nuevamente, que la escuela ha sido la que más ha contribuido a difundir la ideología del mundo occidental en los jóvenes.

En cuanto a la palabra vergüenza. Es alrededor de ella que se desarrolla el discurso de los jóvenes. Vergüenza, se opone a orgullo. No se tiene orgullo por hablar asháninka. En cambio, "no hablar bien castellano" es motivo de vergüenza.

La vergüenza por ser asháninka está presente en los jóvenes. Por ejemplo, al preguntar a uno si sentía orgullo por ser asháninka, la respuesta fue:

Algunas personas no reconocen, a veces, por vergüenza, no quieren hablar.

No contesta sobre el orgullo, contesta sobre la vergüenza. No contesta sobre él mismo, dice que la vergüenza es de algunas personas, aunque lo más probable es que, de alguna manera con la fórmula 'algunas personas' esté también hablando de sí mismo. Pero, por otro lado, y tal como lo vimos antes, los jóvenes dicen sentirse asháninkas así se vistan como mestizos y así hablen castellano. Al preguntárseles sobre el asunto, uno señaló:

Porque somos Asháninkas, si seríamos colonos seguiríamos siendo colonos, si seríamos otras tribus también seguiríamos sintiendo, pero ya aprendimos el castellano, nuestra segunda lengua para poder comunicarnos con los demás, pero si seguimos siendo.

Nótese el uso de pero: somos asháninkas pero ya aprendimos castellano. Es decir que, aunque el hablante no lo reconozca, hay algo que ha cambiado en su ser asháninka. El joven insiste en que sigue siendo asháninka. Se utiliza dos veces la conjunción adversativa pero en un pequeñísimo texto. Se observa, también, que para el joven ser asháninka es pertenecer a una tribu. Tribu es un término que tiene una carga semántica negativa y proporciona un indicio de que estos jóvenes han asimilado los prejuicios de la sociedad hegemónica con respecto a los pueblos indígenas. El castellano es calificado como nuestra segunda lengua. El uso del posesivo indica ese sentido de pertenencia al mundo de los demás. Pertenecer a ese mundo permite comunicarse con los demás. Permite ser parte del mundo de los demás. Uno de los jóvenes señaló que a su hermanita: 
En castellano nomás le hablo. A mi mamá le he dicho que le hablen en castellano nomás porque así comprende la lectura más.

Como se ve, este joven es un convencido de la necesidad de castellanizar. Para él hablar asháninka traerá dificultades en la escuela. Este joven ha hecho suyo uno de los prejuicios de los que no creen en la EIB, el hecho de que la lengua indígena dificulta los aprendizajes. Nótese además que el joven le ha dicho a su mamá que no le hable asháninka a su hermanita. Él no dice que ha sugerido a su madre. Él ya le ha dicho a su mamá. Como si ese joven sintiera que tiene potestad para ordenarle algo a su madre.

Para terminar con este punto, se ha considerado importante presentar otra apreciación de un entrevistado:

El profesor nos decía que teníamos que hablar castellano para que entendamos mejor la lectura y porque una palabra técnica no se puede entender en asháninka pero en castellano sí.

No interesa hablar de la relación entre lengua y enseñanza sino la relación entre técnica y lengua. El estudiante ha asumido como cierta la idea de que el asháninka no es una lengua para las cosas técnicas, a diferencia del castellano que sí sirve para eso. Esta afirmación hace pensar en cuáles son las ideas que tienen los estudiantes sobre la técnica, la ciencia y la lengua, y es ese el tema que se desarrollará en el ítem de la descolonización mental.

Como se ha dicho, los estudiantes no han tenido educación bilingüe intercultural, ellos han sido formados en la escuela castellanizante. La EBI, como se sabe, es la opción pedagógica para los niños indígenas ${ }^{2}$ y, por ello, llama la atención este comentario de un estudiante de educación:

Yo tengo muchas ambiciones ¿no? para viajar cuando termine mis estudios, cuando termine mis estudios, yo no quiero quedarme ahí nomás. Yo quiero seguir estudiando mi carrera es docencia ser un maestro competitivo, porque ahora todo se basa en la competitividad y mi anhelo más grande sería volver a trabajar en mí en mi comunidad pero eso no depende de mí ¿no? Del lugar donde me envíen este... y cuando tenga un trabajo fijo y seguro ayudar en primer lugar a mi familia. 
La comunidad del joven es una comunidad asháninka donde los niños hablan asháninka y tienen derecho a recibir una educación en su lengua y en su cultura. Desde la narrativa del joven, progresar, no quedarse ahí nomás, es ser un maestro competitivo y si bien expresa querer trabajar en su comunidad, no hace ninguna mención a lo que es la EIB. El joven no se está formando en EIB, él se está formando para ir a cualquier lugar donde lo envíen, mestizo o indígena. Ser competitivo es lo importante. Prepararse para ser un maestro EIB ni se menciona.

Cuando se piensa en mejorar la educación de los niños, no se hace referencia a la necesidad de una educación lingüística y culturalmente pertinente:

Mayormente la educación por el río Tambo es muy baja, es muy baja, ¿por qué? porque ahí no es como aquí es decir porque en esta ciudad hay mucha flexibilidad acá en Satipo mismo hay energía para que hagan su trabajo a veces en la rurales no hay luz o fluido para que para busque cuando lo deje los profesores su trabajo para que se vaya en el Internet a sacar sus informaciones.

Según la narrativa del joven, la educación es baja porque no es como la de Satipo. Para que la educación mejore, el joven cree que es necesario tener internet para hacer los trabajos que asigne el maestro. No hay en los estudiantes ninguna conciencia sobre lo que es la pertinencia cultural. Esta narrativa es una muestra de que la mirada es hacia afuera, el ideal de mejorar es parecerse al mundo mestizo.

Es preocupante que jóvenes que se preparan como docentes de niños asháninkas no consideren el derecho de los niños a educarse en su lengua y desde su cultura. Las narrativas de los futuros docentes muestran cómo se ha internalizado el discurso de las élites y se asume que el camino es una educación castellanizante:

- ¿Deberían enseñar asháninka en las escuelas?

- En primaria sí, pueden enseñar bilingüe, porque en colegio ya son mayores, pueden entender castellano rápidamente.

Si bien se preguntó por la enseñanza de la lengua, la respuesta fue sobre el uso de la lengua en la enseñanza. El entrevistado, quien se está formando en educación, considera que el asháninka puede usarse en primaria. Para el joven la cuestión de usar asháninka o no es condicional al conocimiento de castellano 
que tenga el niño. Por eso es que, al referirse a la educación secundaria ${ }^{3}$, considera que ya no habría ninguna necesidad de usar el asháninka, puesto que ya los niños tendrían suficiente conocimiento del castellano para desarrollar todos sus aprendizajes en esa lengua. Llama la atención la comparación que se hace entre ser mayor y entender castellano. Parece que no es solo una cuestión de que se va aprendiendo el castellano con los años, sino que tiene que ver con todas las connotaciones que tiene hablar dicha lengua. Esto se verá más claro con este otro ejemplo:

- ¿Por qué solo castellano?

- Porque ya son mayores y pueden entender castellano. Ya tienen esa vocación de conocer castellano. Yo también me hice así, claro, de primaria.

Estas narrativas asumen que entender castellano es una vocación, una inclinación hacia el mundo de afuera, que habla castellano. Para el estudiante la educación en esta lengua es la correcta porque así se ha hecho siempre: yo también me hice así comenta el joven. Justifica, entonces, el dejar el asháninka porque así lo hacen todos. La manera de crecer, de ser mayor, es entender el castellano y ya no necesitar el asháninka.

Otro punto que interesa tocar es el que se refiere a la opinión sobre el uso del asháninka en los medios de comunicación:

- ¿Hay radio en asháninka? si hubiera, ¿qué tipos de programa te gustaría escuchar? ¿Música o noticias?

- Música y noticias para que se entere la gente porque como hablan asháninka, entienden mejor en asháninka.

En esta narrativa, el entrevistado se aleja de los asháninkas. No dice mis paisanos, no usa la forma nosotros. Se les dice la gente. La pregunta es por los gustos del joven en la radio, si es que se hiciera radio en asháninka. Pero él no dice nada de sí mismo. Quizá a él no le interese la radio en asháninka porque, como se ha visto arriba, para los jóvenes, es un idioma que se usa con los que no entienden castellano. La radio en asháninka, entonces, no lo involucra a él sino a los que entienden mejor el asháninka que el castellano: a la gente. 
Cuando se le preguntó a uno de los jóvenes qué problemas encontraba en lo que se refiere al uso de su lengua en su comunidad, él manifestó que la lengua se estaba perdiendo porque muchos padres y madres no quieren enseñar a sus hijos el idioma. Esta narrativa muestra, por primera vez, una preocupación ante la pérdida de su lengua. El joven es consciente de que los padres ya no hablan asháninka a sus hijos y los considera responsables de la pérdida de la lengua. No se entrará en detalles sobre esa identificación de responsables. Interesa señalar que esta ha sido la única narrativa en la que se muestre preocupación ante la pérdida de la lengua.

2.4. Quitar énfasis de sus aspectos positivos propios: Se naturaliza la idea de que el saber "occidental" es el mejor: "Los que han estudiado son mejores porque ahí nomás piensan".

Todos los jóvenes que hemos entrevistado creen que la única forma de desarrollarse está en la educación superior. Tomemos esta narrativa de uno de los jóvenes:

El problema del asháninka es que recién se está preparando recién se está capacitando; en el futuro yo creo que eso va a mejorar porque recién hay profesionales que se está preparando, así como Miqueas es la primera promoción ¿no? que va a ser de los que han ingresado los jóvenes del Río Tambo a través de la organización que la municipalidad, a través de ellos recién de ahí todavía seguimos ya los demás que hemos entrado ya, los demás promociones así es.

La comunidad necesita profesionales para mejorar. Se concibe que solo a partir de la educación superior se está preparado. Al no haber profesionales asháninkas, es un pueblo que no está preparado ni capacitado. Esta idea es recurrente entre los jóvenes asháninka. Uno de los entrevistados, por ejemplo, cuando le preguntamos por qué es importante la educación superior, nos contestó:

Los que han estudiado son mejores porque así nomás piensan.

En este enunciado el conector porque se utiliza para establecer una equivalencia entre estudiar y pensar. Solo quienes han estudiado piensan, esto además se ve reforzado por el marcador textual así nomás. 
Se establece la identificación entre estudios y pensamiento. Para ser mejor hay que acceder a los estudios que imparte el mundo occidental. Se consideran como válidos solo los conocimientos del mundo occidental. Esta narrativa omite los saberes propios. Ya se han analizado narrativas que descalifican a la lengua, en lo que sigue mostramos una narrativa en la que descalifican los conocimientos propios:

Sí me gustaría volver a mi comunidad, regresar ahí, organizar a mis trabajadores, como técnico que estoy siguiendo la especialidad de Agropecuaria y hay mucho que hacer por mi comunidad, y hay mucho terreno para poder cultivar y crecer ¿no? porque ahorita mayormente todos los comuneros de allá lo cultivan de una manera empírica no lo hacen un manejo técnico hace poco recién está haciendo.

Como se observa, el estudiante de agropecuaria descalifica el hecho de que en su comunidad no se cultiven todos los terrenos. Él dice que hay mucho terreno para cultivar y que los comuneros no lo hacen. Se saber, sin embargo, que el hecho de no sembrar todo el terreno no tiene que ver con que los asháninkas no sepan de técnicas sino, por el contrario, porque su conocimiento de suelos les hace cuidarlos y dejarlos en descanso. Así un conocimiento indígena de sabiduría ancestral es despreciado por el joven que estudia agropecuaria en una zona donde se depreda el medio ambiente.

Pero el asunto es todavía más grave si se observa que al inicio de esta narrativa el joven se refiere a los comuneros como mis trabajadores, es decir, emplea un término que podría ser esperable en un gamonal, más no en un joven que está estudiando para ayudar a su comunidad. Aquí es cuando el discurso hegemónico se ve con más claridad en el discurso del entrevistado: no se refiere a los otros como trabajadores sino como mis trabajadores, como si fueran de su propiedad.

Los estudiantes salieron de una escuela "civilizadora y colonizadora" y ahí aprendieron a sentir vergüenza de hablar asháninka (recuérdese que se dijo que los padres que no han ido a la escuela no se avergüenzan de hablarlo) Ahora están en instituciones de educación superior que les enseñan a conocer como válidas solo las formas occidentales de conocimiento. Todo lo otro es empírico y no técnico. El conocimiento y el saber es el saber de quienes tienen el poder y es ese conocimiento el que se transmite a los estudiantes. 
En estas narrativas se desprecia a los comuneros que no tienen los conocimientos que valora el mundo occidental. Se dice que los líderes y autoridades no saben. Se piensa que como muchos líderes no saben aquello que es reconocido por la cultura mestiza, no están preparados para el cargo.

Todos los entrevistados creen que un requisito indispensable para ser líder es estar preparado como profesional.

Los jóvenes reconocen la validez del conocimiento que les dan en su formación superior y también califican positivamente el que reciben en los talleres convocados por la Municipalidad de Río Tambo:

Gracias también estos talleres que estamos realizando como liderazgo juvenil y esto para mí ha sido muy impulsante porque gracias a esos conocimientos que imparten los profesionales a lo menos ya estoy llevando un granito de arena en mi comunidad, y de eso quedo muy agradecido ¿no? A los profesionales que ellos vienen esforzándose en venir aquí para que nos impartan su conocimiento a nosotros que somos conocidos como personas que todavía no conocemos lo que es. Total y ahora como recién estamos entrando en primer paso es ya tener captar todo el conocimiento de las demás personas que ya son profesionales y llevar a mi pueblo a impartir a ellos esos conocimientos que yo también tengo entonces gracias a ellos también van a poder llegar a ser personas que también van a conocer que pasa en la realidad.

Los profesionales imparten conocimiento. Esto se expresa dos veces en la narrativa del joven. Los profesionales se esfuerzan en ir a Satipo. Ellos no se sienten merecedores de ese privilegio. Él se considera una persona que todavía no conoce lo que es. Su misión es asimilar los conocimientos que le imparten. Él no piensa en un aprendizaje reflexivo, él debe absorber todo el conocimiento de los profesionales y llevarlo a sus paisanos para que conozcan las cosas, tal y como son en realidad. Los paisanos, al igual que ellos, todavía no conocen las cosas como son. Los conocimientos propios no son los válidos, para conocer lo que pasa en realidad hay que tener los conocimientos de los profesionales.

Un nuevo ejemplo del desprestigio que le han asociado los jóvenes a los saberes indígenas, lo apreciamos en este discurso: 
A nivel de asháninkas tiene muchísimo, muchísimo problemas y tiene que ver necesitan primero es primero está en la educación porque sin la educación uno se puede hablar nada de progreso de hacer cosas bien dentro de tu comunidad.

El pueblo asháninka se concibe como atrasado (no se puede hablar de progreso) y ello es debido a que hace falta educación; por educación se concibe solo la impartición de los conocimientos de fuera. Esa idea de que se está ante un pueblo atrasado la encontramos dramáticamente expresada en el discurso de un mestizo (puesto que en el grupo de estudiantes no hay solo asháninkas sino también mestizos):

Desde de un punto de vista yo veo que está pasando en los asháninkas es que recién este están, ¿cómo se puede decir- están civilizando están viendo que los colonos por ejemplo cultivan para obtener ganancias ingresos entonces los asháninkas están viendo ese que cuanto más cultivo más venden entonces viven mejor los civiles, tienen carros este mayor acceso a salen a los bares se divierten entonces ven eso los asháninkas por ejemplo más que nada los de parte de adentro no lo que es puro campo ahí los asháninkas ven recién están como te vuelvo a decir este, civilizados.

En esta narrativa se observa que una muestra de que los asháninka se estén civilizando es que empiezan a depredar el terreno, como los mestizos, al dedicarse a la agricultura. El mestizo abiertamente dice que los asháninkas son primitivos, que recién están en camino a ser civilizados y que esa civilización les viene porque reproducen las prácticas de los mestizos. El mestizo es parte del grupo de estudiantes y hace ese comentario frente a todos los asháninkas.

Para el mestizo, lo que dice no es algo incorrecto; es algo de lo que él está convencido y es algo que los jóvenes presentes no refutan, a pesar de que se les preguntó qué piensan de esto.

Como es obvio, estas creencias, percibidas a partir de la conversación con jóvenes, son poco favorables para el trabajo que viene realizando la institución. Si de lo que se trata es de formar líderes para el pueblo asháninka, es necesario que estos líderes se distingan y tomen distancia de la forma de pensar de la cultura mestiza. Es necesario que valoren sus propias prácticas culturales y miren con más cariño su cultura y su lengua. Si no, no podrán ser líderes para 
su pueblo. Es necesario que se capaciten; pero es necesario que comprendan que los conocimientos de sus padres y abuelos son también valiosos y no los echen por la borda.

2. 5. Subvalorar los aspectos positivos de la propia cultura y magnificar a la cultura mestiza.

Cuando se ha preguntado a los jóvenes qué es lo que más valoran de la cultura asháninka, la mayoría se ha referido a la comida. Afirmaciones como la siguiente fueron recurrentes:

Nuestra gastronomía. Bueno a mí me gusta más la gastronomía ¿no? Y bueno estando en nuestra comunidad nos gusta nuestra gastronomía. Más bien aquí en la ciudad como no se encuentra las comidas que hay acá. Y si es que no hay de nuestra comunidad acá bueno. Acá ya lo venden, cuesta, pero allá.

Uno de los entrevistados nos dijo:

Una motivación y orgullo del asháninka es su danza. El hombre con su bombo y la mujer cultivan la naturaleza con diferentes contenidos. Por ejemplo, mi mamá, después de la subversión, empezó a cantar otro tipo de cantos. Se realizaron nuevas fiestas, cantos y danzas: «ritmo de guerrilleros». El hombre mientras baila esquiva con movimientos ágiles la piedra que es tirada por la mujer. La piedra representa la escopeta. Hace una representación de lo que fue la subversión, pero ahora el hombre asháninka no muere, sino que esquiva la piedra, la bala de escopeta, y vive.

Como se observa, los valores de la cultura asháninka se reducen a lo que es el folklore. Sin embargo, más allá de lo folklórico, se observa que el arte tiene un papel importante como terapéutico, como para recordar y no olvidar. Esto que cuenta el joven sobre la danza puede servir para pensar en el trabajo de autoafirmación cultural a través del arte. Aun así, nadie menciona el conocimiento indígena.

Cuando se les ha preguntado por lo que les gusta de la cultura mestiza, todos han señalado que la electricidad e internet. Los jóvenes ven en la cultura mestiza el progreso y el bienestar. Para ellos, al igual que para cualquier joven mestizo, el estudio es lo que permite superación y ascenso social. Parece que lo que ellos desean es tener un trabajo estable en Satipo o en cualquier otra ciudad. 
Los jóvenes estudiantes están en un proceso de enajenación. Y en su discurso se alejan cada vez más de los asháninkas y se acercan a los mestizos. El uso de pronombres ellos/nosotros nos revela que cuando hablan de sus paisanos asháninkas no se refieren a ellos como nosotros sino como ellos. Las ideas de superioridad, de que los comuneros son de su propiedad, esas formas de referirse a los subordinados que tienen las elites, se hacen presentes en los discursos de los jóvenes, tal como se analizó en el discurso del joven que hablaba de mis trabajadores; quien dijo esto no se identifica como miembro de la comunidad y se refería a los asháninkas de su pueblo como los comuneros de allá. Él no será ya comunero, el será técnico en su comunidad. Él es portador del saber y, por lo tanto, del poder. El uso de posesivos para referirse a los otros asháninkas es recurrente:

Nosotros y lo que nosotros tenemos que hacer es no defraudarlos a nuestros a nuestros comuneros que ponen su lista o su confianza en nosotros.

Nuevamente se está ante una frase aparentemente noble, pero se dice que los comuneros son nuestros. Ese sentimiento de propiedad es típico de las élites dominantes.

A mí sí me gustaría ser líder representar a mi comunidad eh... sacar adelante porque nuestra comunidad bastante nos necesita y no hay muchos profesionales que se están preparando son pocos por ejemplo si queremos crear una organización una cooperativa no hay quien nos dirija, no hay profesionales, y por lo tanto, por esa justa razón es que yo tengo esa ambición de seguir estudiando de superarme y así no buscar personal de afuera de otros lugares traer que estén trabajando no es que nosotros mismo generar eso a trabajar y liderar en esas que creamos una empresa liderar en empresa o cooperativa que podamos crear.

Esta narrativa es otra muestra de la oposición que hacen los jóvenes de entre nosotros y la comunidad. La comunidad carece de profesionales y nosotros somos esos profesionales que antes no había. Nuevamente, la oposición entre los que no saben y los que saben.

Se observa que dentro de una idea de servir a la comunidad la narrativa asume que los jóvenes estudiantes forman parte de una élite: no hay muchos profesionales, esa élite se erigirá como la nueva clase dirigente, ellos serán quienes dirijan a esa comunidad que, hasta el momento, se encuentra sin nadie que los dirija. 


\section{Conclusiones}

1. La investigación buscaba averiguar si los jóvenes estudiantes asháninkas que han migrado de sus comunidades para realizar estudios profesionales en la ciudad de Satipo, al estar imbuidos en un medio discriminador, habían asimilado el discurso racista; es decir si este influía en su concepción sobre ellos mismos, sobre su identidad y sobre su cultura. Es importante recordar que este no es un método común en el ACD, que normalmente estudia el discurso de las élites y no el de los subalternos, pero parecía que este análisis podría dar indicios para trabajar en el futuro y se han encontrado resultados reveladores: los jóvenes estudiantes viven en un ambiente racista y discriminador, donde se les considera incivilizados. La investigación ha demostrado que este ambiente ha influido en la autoconcepción que tienen los asháninkas sobre sí mismos.

2. Una de las formas en las que el discurso racista ha penetrado en los jóvenes asháninkas es en el menosprecio a su lengua. Se está en un proceso acelerado de desplazamiento lingüístico. Los jóvenes hablan más castellano no solo porque el contexto de la ciudad los obliga, sino que ellos mismos son los propiciadores de ese desplazamiento. Recuérdese al estudiante que señaló que ya le ha dicho a su mamá que no le hable asháninka a su hermanita.

3. La colonización mental de los jóvenes es evidente. Ellos creen que solo se puede hablar de un tipo de educación y de un tipo de conocimientos válidos y estos son los conocimientos de los profesionales que "ven las cosas como son." El discurso hegemónico llega desde las élites y se asienta en su vida cotidiana de una manera muy profunda y si bien es preocupante, también es comprensible dado el contexto en el que estos jóvenes se desenvuelven. Vivir en un ambiente racista y de negación e invisibilización del otro ha afectado la autoestima cultural de los estudiantes asháninkas. Hay vergüenza por la lengua asháninka. Se afirma que es un dialecto, en el sentido peyorativo del término, y que solo debe usarse cuando la gente no habla castellano. El castellano, en cambio, es necesario para salir adelante. Los estudiantes están debilitados culturalmente y no encuentran, más allá de la comida o la danza, ningún aspecto positivo en su cultura. Incluso, la depredación de la Amazonía que trastoca las formas de la agricultura asháninka es juzgada positivamente por asháninkas que estudian agropecuaria y afirman que el monocultivo intensivo, forma de agricultura mestiza, es la válida.

4. La asimilación del discurso hegemónico tiene su razón de ser en el hecho de que los jóvenes estudian en instituciones mestizas en las que no se los prepara para desenvolverse en su comunidad, así están expuestos a todas las formas de 
discriminación, lo cual los obliga a invisibilizarse para salir adelante. Y esto significa tratar de parecerse más a los mestizos.

5. Ha quedado ampliamente demostrado que los jóvenes asháninkas han asimilado el discurso de las élites y es posible, entonces, reformular para este caso el cuadrado ideológico/valórico del discurso racista de Van Dijk, no aplicado a las élites sino a los asháninkas que han internalizado su discurso: Expresar/ Enfatizar información positiva sobre las élites. Expresar / Enfatizar información negativa sobre sí mismos. Suprimir / Desenfatizar información positiva sobre sí mismos. Suprimir/Desenfatizar información negativa sobre las élites.

\section{Referencias bibliográficas}

Bourdieu, P., \& Wacquant, L. (1995). Por una antropología reflexiva. México: Grijalbo.

Comisión de la Verdad y la Reconciliación. (2003). Informe Final de la Comisión de la Verdad y la Reconciliación: Tomo $V$

Infante, M. (2010). Desafíos para la formación docente: Inclusión educativa. Estudios Pedagógicos, 36(1), 287-297. Recuperado de http://www.scielo. cl/scielo.php?pid=S0718-07052010000100016\&script=sci_arttext el 24 de noviembre de 2017

Rivera Cusicanqui, S. (1993). La raíz: colonizadores y colonizados. Violencias encubiertas en Bolivia, 1, 25-139.

Rivera Cusicanqui, S. (2003) Oprimidos, pero no vencidos: luchas del campesinado aymara y qhechwa, 1900-1980. Aruwiyiri: Editorial del Taller de Historia Oral Andino (THOA).

Rivera Cusicanqui, S. (2010) Ch’ixinakax utxiwa: una reflexión sobre prácticas y discursos descolonizadores - 1a ed. - Buenos Aires: Tinta Limón.

Rivera Cusicanqui, S. (2014) La disponibilidad de lo inédito: entrevista a Silva Rivera Cusicanqui. Recuperado de: http://anarquiacoronada.blogspot. pe/2014/04/la-disponibilidad-de-lo-inedito.html el 15 de mayo de 2017

Schiffrin, D. (2015). Discourse Markers: Language, Meaning, and Context. En: Tannen, D., Hamilton, H. E., Schiffrin, D. (2015). The handbook of discourse analysis. Oxford, Inglaterra. Blackwell Willey 
Schieffelin, B. B., Woolard, K. A., y Kroskrity, P. V., (Eds.). (1998). Language ideologies: Practice and theory. Oxford, UK: Oxford University Press.

Tannen, D., Hamilton, H. E., Schiffrin, D. (2015). The handbook of discourse analysis. Oxford, Inglaterra. Blackwell Willey

Van Dijk, T. A., (1997). Discourse Studies. A Multidisciplinary Introduction. London, UK: Sage

Van Dijk, T. (2001). Discurso y racismo. Recuperado de http://www.discursos. org/oldarticles/Discurso\%20y\%20racismo.pdf el 24 de noviembre de 2017

Van Dijk, T. (2005). Ideología y análisis del discurso. Utopía y praxis latinoamericana, 10(29). Revista Internacional de Filosofía Iberoamericana y Teoría Social. 10, (29), abril-junio pp. 9-36. Universidad del Zulia Maracaibo, Venezuela. Recuperado de https:/dialnet.unirioja.es/descarga/ articulo/2734720.pdf el 11 de junio de 2017.

Van Dijk, T. A. (2006). Ideología. Una Aproximación Multidisciplinaria. Barcelona, España: Gedisa.

Van Dijk, T. A. (2008). Semántica del discurso e ideología. Discurso y Sociedad, 2(1), pp.201-261.

Van Dijk, T. A., (2010). Discurso, Conocimiento, Poder y Política. Hacia Un Análisis Crítico Epistémico Del Discurso. Revista de Investigación Lingüística, 13, pp. 167-215.

Van Dijk, T. A. (2011). Discurso y Poder. Barcelona, España: Gedisa.

Van Dijk, T. A. (2013). Discurso y Contexto. Barcelona, España: Gedisa.

\footnotetext{
${ }^{1}$ Este artículo forma parte de un capítulo de la tesis de Maestría en lingüística de la UNMSM: El racismo discursivo de las élites, la colonialización mental a los jóvenes asháninkas y la lucha contradiscursiva. Una investigación desde el Análisis Crítico del Discurso. Asesorada por Elsa Vílchez.

${ }^{2}$ Si bien sabemos de resultados no exitosos en las llamadas escuelas EIB, creemos que cuando sí se hace EIB esta es la mejor alternativa para desarrollar aprendizajes en los niños indígenas.

${ }^{3}$ Cuando los jóvenes hablan de escuelas aluden a la educación primaria y cuando hablan de colegios, a la secundaria.
} 